\title{
Anti-inflammatory potential of PI3K $\delta$ and JAK inhibitors in asthma patients
}

\author{
Thomas Southworth ${ }^{1 *}$, Jonathan Plumb1, Vandana Gupta', James Pearson', Isabel Ramis ${ }^{2}$, Martin D. Lehner², \\ Montserrat Miralpeix ${ }^{2}$ and Dave Singh ${ }^{1}$
}

\begin{abstract}
Background: Phosphatidylinositol 3-kinase delta (PI3K $)$ and Janus-activated kinases (JAK) are both novel anti-inflammatory targets in asthma that affect lymphocyte activation. We have investigated the anti-inflammatory effects of PI3K and JAK inhibition on cytokine release from asthma bronchoalveolar lavage (BAL) cells and T-cell activation, and measured lung PI3K $\delta$ and JAK signalling pathway expression.
\end{abstract}

Method: Cells isolated from asthma patients and healthy subjects were treated with PI3K $\delta$ or JAK inhibitors, and/or dexamethasone, before T-cell receptor stimulation. Levels of IFNY, IL-13 and IL-17 were measured by ELISA and flow cytometry was used to assess T-cell activation. PI3KS, PI3KY, phosphorylated protein kinase B (pAKT) and Signal Transducer and Activator of Transcription (STAT) protein expression were assessed by immunohistochemistry in bronchial biopsy tissue from asthma patients and healthy subjects. PI3K $\delta$ expression in BAL CD3 cells was measured by flow cytometry.

Results: JAK and PI3K inhibitors reduced cytokine levels from both asthma and healthy BAL cells. Combining dexamethasone with either a JAK or PI3K $\delta$ inhibitor showed an additive anti-inflammatory effect. JAK and PI3K $\delta$ inhibitors were shown to have direct effects on T-cell activation. Immunohistochemistry showed increased numbers of PI3K expressing cells in asthma bronchial tissue compared to controls. Asthma CD3 cells in BAL expressed higher levels of PI3K protein compared to healthy cells.

Conclusions: Targeting PI3K $\delta$ or JAK may prove effective in reducing T-cell activation and the resulting cytokine production in asthma.

Keywords: Asthma, Phosphatidylinositol 3-kinase delta, JAK/STAT, T-cell cytokines, Bronchoscopy

\section{Background}

Airway inflammation is a key feature of asthma. There are increased lymphocyte numbers in the lungs of patients with asthma, with many patients showing a T-helper 2 (TH2) response, associated with eosinophilic inflammation [1]. However, there is also evidence of an increased T-helper 1 (TH1) response in asthma, with IFN $\gamma$ overproduction [2], and a role for T-helper 17 (TH17) cells in promoting neutrophilic inflammation in asthma [3].

Inhaled corticosteroids (ICS) are the most widely used anti-inflammatory treatments for asthma. However, many patients with moderate to severe asthma suffer

\footnotetext{
* Correspondence: tsouthworth@meu.org.uk

${ }^{1}$ The University of Manchester; Division of Infection, Immunity \& Respiratory Medicine; Manchester Academic Health Science Centre; University Hospital South Manchester NHS Foundation Trust, Southmoor Road, Manchester M23 9LT, UK Full list of author information is available at the end of the article
}

with persistent symptoms despite the use of high doses of ICS [4]. Novel anti-inflammatory therapies are needed for asthma patients. Novel drugs that target lymphocyte cytokine production may be of therapeutic benefit in asthma.

Most pro-inflammatory cytokines signal through Janus Kinase (JAK) proteins following binding to cytokine receptors, resulting in activation of signal transducer and activator of transcription (STAT) proteins [5]. STATs act as transcription factors, and play a key role in lymphocyte differentiation and activation; IL-12 induces STAT4 activation promoting TH1 differentiation, IL- 4 activates STAT6 promoting TH2 differentiation and IL-6, IL-21 and IL-23 all stimulate STAT3-dependent TH17 differentiation $[6,7]$. 
Another intracellular kinase that controls lymphocyte function is $\mathrm{PI} 3 \mathrm{~K} \delta$; this lipid kinase is involved in lymphocyte activation, proliferation and differentiation. T-cell receptor (TCR) stimulation results in activation of the PI3K $\delta /$ pAKT pathway [8-10], and PI3K $\delta$ inhibition reduces TCR stimulated cytokine production from healthy human peripheral blood lymphocytes [11].

Animal models have demonstrated roles for PI3K $\delta$ and JAK/STAT signalling in airway inflammation [12-14]. Drugs that target PI3K $\delta$ or JAK have the potential to suppress lymphocyte activation in asthma. We sought to provide validation of these novel drug targets by investigating their function and expression using lung cells and tissues from patients with asthma. The aims of this study were to evaluate the anti-inflammatory effects of PI3K $\delta$ and JAK inhibition on release of T-cell derived cytokines from asthma bronchoalveolar lavage (BAL) cells, and to investigate activation of these pathways in asthma patients compared to healthy subjects by immunohistochemical analysis of PI3K $\delta$, PI3K $\gamma$, pAKT and pSTAT proteins in bronchial biopsies. We also investigated the potential additive anti-inflammatory effects of a JAK or PI3K $\delta$ inhibitor used with a corticosteroid on cytokine production from asthma lymphocytes, and the effects of these drugs on T-cell activation.

\section{Methods}

\section{Patients}

Twenty five moderate to severe asthma patients and 21 healthy subjects were recruited for bronchoscopy (see Table 1 for clinical characteristics). BAL cells were collected from 12 asthma patients and 11 healthy subjects for cytokine analysis, while biopsies were collected from 13 asthma and 12 healthy subjects; some patients provided both samples (8 asthma patients and 9 healthy subjects). BAL cells from 9 asthma patients and 6 healthy subjects were used for pSTAT5 and/or PI3K $\delta$ analysis. All BAL cells were used for cell culture or flow cytometry; due to limited cell numbers, no cytospins for differential cells counts were collected. In order to estimate the percentage of lymphocytes present in BAL samples, we performed differential cell counts on BAL cytospins collected historically for research purposes. The clinical features of these 36 asthma patients and 15 healthy subjects are described in Additional file 1: Table S1. Blood was collected from a total of 5 asthma patients and 15 healthy subjects. These participants differed from those undergoing bronchoscopy (clinical features are summarised in Additional file 1: Table S1). Asthma patients were using ICS at a dose $>800 \mu \mathrm{g} /$ day beclomethasone equivalent, had an asthma control questionnaire (ACQ) score $>1$, and demonstrated $>12 \% \mathrm{FEV}_{1}$ reversibility to salbutamol or a methacholine $\mathrm{PD}_{20}<$ $16 \mathrm{mg} / \mathrm{ml}$. Healthy subjects had no history of chronic respiratory disease and had no evidence of airflow
Table 1 Demographics, clinical characteristics and BAL cell yields for bronchoscopy subjects

\begin{tabular}{lll}
\hline & Healthy & Asthma \\
\hline Number & 21 & 25 \\
Sex $(\mathrm{m} / \mathrm{f})$ & $10 / 11$ & $13 / 12^{*}$ \\
Age & $38.5+/-13.1$ & $43.8+/-12.0^{*}$ \\
Age of asthma diagnosis & $\mathrm{N} / \mathrm{A}$ & $16.1+/-16.0$ \\
Body Mass Index & $25.7+/-3.5$ & $27.3+/-3.3^{*}$ \\
Atopy $(\mathrm{Y} / \mathrm{N})$ & $1 / 20$ & $21 / 4^{\mathrm{a}}$ \\
ACQ score & $\mathrm{N} / \mathrm{A}$ & $1.85+/-0.79$ \\
FEV1 \% predicted & $103.7+/-17.2$ & $72.4+/-15.5^{* * *}$ \\
FEV1/FVC & $78.8+/-5.4$ & $65.8+/-10.4^{* * *}$ \\
Reversibility $\%$ ) & $3.2+/-2.6$ & $18.9+/-17.4^{* *}$ \\
SABA $(y / n)$ & $0 / 21$ & $24 / 1^{\text {a }}$ \\
LABA $(y / n)$ & $0 / 21$ & $21 / 4^{\text {a }}$ \\
ICS $(y / n)$ & $0 / 21$ & $25 / 0^{* *}$ \\
Beclomethasone dose $(\mu g /$ day $)$ & 0 & $1125+/-558$ \\
BAL cell yields $\left(\times 10^{6} / \mathrm{ml} \mathrm{BAL)}\right.$ & $0.099+/-0.038$ & $0.107+/-0.072^{*}$
\end{tabular}

Data is presented as mean $+/-$ standard deviation. Comparisons between groups were by T-test: ${ }^{*} p>0.05$; ${ }^{* *} p<0.01$; ${ }^{* * *} p<0.001$, or by Chi-square test: ${ }^{\mathrm{a}} p<0.001$

Abbreviations: $A C Q$ asthma control questionnaire, $F E V_{1}$ Forced expiratory volume in one second, FVC forced vital capacity, SABA short acting $\beta$-agonist, $\angle A B A$ long acting $\beta$-agonist, ICS inhaled corticosteroid; $N / A$ not applicable

obstruction or a chest infection within 4 weeks prior to recruitment. All subjects were never smokers. Subjects were excluded if they had any history of non-asthmatic lung disease or an asthma exacerbation within 4 weeks prior to recruitment, as defined by a worsening in symptoms requiring a change in treatment and/or hospitalization. The study and sample collection was approved by the local research ethics committee (Bronchoscopy: NRES Committee North West - Greater Manchester South; REC Ref: 06/ Q1403/156; Blood: North West Preston Research Ethics Committee, REC Ref: 10/H1016/25; Resected lung tissue for immunohistochemistry controls: South Manchester Research Ethics Committee, REC Ref: 03/SM/396) and all subjects provided written informed consent.

\section{Cell collection and culture}

The methods are fully described in the online Additional file 2: Supplementary Method. Briefly, BAL cells were treated with either a JAK inhibitor, tofacitinib (previously named CP-690550) [14], a PI3K $\delta$ inhibitor, PIK-294, [15] (both synthesized in the Department of Medicinal Chemistry of Almirall R\&D, Sant Feliu de Llobregat, Barcelona, Spain) or dexamethasone (Sigma-Aldrich, Poole, UK) for $1 \mathrm{~h}$ before addition of $5 \mathrm{ng} / \mathrm{ml} \mathrm{CD3}$ (ExBio, Vestec, Czech Republic product code: $12-631-\mathrm{C} 100)$ and $10 \mathrm{ng} / \mathrm{ml} \mathrm{CD} 28$ (Biolegend, London, UK product code: 302913) antibodies to induce a T-cell receptor (TCR) specific response. Enzymatic profiles of tofacitinib [16] and PIK-294 [15] are shown 
in Additional file 3: Table S2. Cytotoxic effects of the drugs were assessed in TCR-stimulated PBMCs by Pierce LDH assay (Life Technologies, Paisley, UK) and propidium iodide flow cytometry assay (BD Bioscience, Oxford, UK); Additional file 4: Figure S1. When sufficient cells allowed, dexamethasone (1-10000nM) with 100nM of tofacitinib or PIK-294 were added before TCR stimulation; 100nM was chosen as it demonstrated submaximal inhibition of IFNy from BAL cells from the first 3 patients. For PIK-294, $100 \mathrm{nM}$ also showed selectivity for PI3K $\delta$ over other PI3K isoforms (see Additional file 3: Table S2). BAL cells were depleted of T-cells using the EasySep Human CD3 positive selection kit (Stemcell Technologies, Cambridge, UK); flow cytometry demonstrated that between 95.6 and $100 \%$ of $\mathrm{BAL} \mathrm{CD}^{+}$cells were removed.

\section{Cytokine analysis}

IL-13, IFN $\gamma$, IL-17, TGF- $\beta$ and IL-12 were measured in cell culture supernatants by "Ready-Set-Go!" ELISA (eBioscience, UK). Lower levels of quantification (LLOQ) for all assays were $4 \mathrm{pg} / \mathrm{ml}$. IL-6 was measured by Duoset ELISA (R\&D Systems, Abingdon, UK); LLOQ was $9.4 \mathrm{pg} / \mathrm{ml}$.

\section{Flow cytometric analysis of pSTAT5 and PI3K $\delta$}

Lymphocytes were isolated from blood using a Human Tcell isolation Kit (Stemcell Technologies, Cambridge, UK). Purity was assessed by flow cytometry, with a mean $\mathrm{CD}^{+}$ count of $94.2 \%$. Purified T-cells were treated with 1000nM Dexamethasone, PIK-294 and tofacinib for $1 \mathrm{~h}$ before TCR-stimulation for $4 \mathrm{~h}$. Cells were fixed, permeabilised, and labelled with CD3 and pSTAT5 antibodies. Analysis was carried out on a CANTO II flow cytometer (BD Biosciences, Oxford, UK). Full methods are in the online Additional file 2: Supplementary Method.

BAL cells were fixed, permeabilised, and labelled with CD3 and PI3K $\delta$ antibodies. Analysis was carried out on a CANTO II flow cytometer (BD Biosciences, Oxford, UK). Full methods are in the online Additional file 2: Supplementary Method.

\section{Immunohistochemistry}

Analysis of pSTATs 1, 3, 5 and 6, pAKT, PI3K $\delta$, PI3K $\gamma$ and CD3 were carried out by immunohistochemistry on bronchial biopsies, with analysts being blinded to subject classification. Full methods are in the online Additional file 2: Supplementary Method and Additional file 5: Table S3.

\section{Statistical analysis}

Data distribution was determined by KolmogorovSmirnov test. Clinical characteristics were normally distributed and comparisons between groups by T-test or Chi-square test. Absolute IFN $\gamma$ and IL-13 levels were normally distributed, while IL-17 was distributed non- parametrically. Intragroup analysis of drug effects was by ANOVA with Bonferroni post-hoc test for parametric data or Friedman test with Dunn's post-hoc test for IL17 data, and used absolute cytokine values. Percentage inhibition data was all parametrically distributed. Asthma vs healthy comparisons for the percentage inhibition effect of each drug on each cytokine were by 2way ANOVA. Comparisons of the percentage inhibition effects for each drug between cytokines were by 2-way ANOVA with Tukey multiple comparison test. $\mathrm{IC}_{35}$ values, as well as $\mathrm{IC}_{50}$, are presented as $>50 \%$ inhibition was not always achieved for IL-17. The effects of dexamethasone with or without 100nM tofacitinib or PIK-294 were evaluated by 2-way ANOVA with Sidak post-hoc test. STAT5 activation and IL-6 levels were normally distributed; drug effects were analysed by 1 way ANOVA with a Dunnett's multiple comparison test against the stimulated control. Comparisons of pAKT, PI3K $\gamma$, pSTAT6 and CD3 PI3K $\delta$ expression between healthy subjects and asthma patients were by T-test as the results were normally distributed, while other immunohistochemistry markers were compared using Mann-Whitney test as these were non-parametrically distributed. All statistical analysis was performed using Prism 6.04 (http:// www.graphpad.com).

\section{Results}

The demographics of the participants who underwent bronchoscopy are shown in Table 1. For asthma patients, the mean ACQ score was 1.85 and the mean $\mathrm{FEV}_{1}$ was $72.4 \%$ predicted, indicating moderate to severe symptomatic asthma. The age, body mass index and BAL cell yields were similar between groups.

\section{TCR activation of BAL cells}

TCR stimulation of BAL cells from asthma patients $(n=12)$ and healthy subjects $(n=11)$ was performed; IL-13 levels were higher in stimulated asthma compared to healthy cells (means 370 versus $130 \mathrm{pg} / \mathrm{ml}$ respectively; $p=0.02$ ). There were no other differences between groups in either basal or stimulated conditions (Additional file 6: Table S4).

\section{Effects of inhibition of PI3K $\delta$ and JAK on TCR responses in BAL cells}

Both JAK (tofacitinib) and PI3K $\delta$ (PIK-294) inhibitors suppressed TCR stimulated IFN $\gamma$, IL-13 and IL-17 production (Fig. 1). The percentage inhibitions observed were similar in asthma patients compared to healthy subjects, with all 2-way ANOVA $p$ values $>0.05$. The $\%$ inhibitions observed at the highest drug concentration $(10 \mu \mathrm{M})$ ranged from 52 to $93 \%$ for PIK-294, and 80 to $96 \%$ for tofacitinib and did not differ between subject groups (Table 2). PIK-294 and 


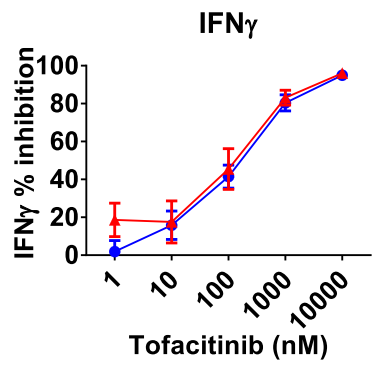

IFN $\gamma$

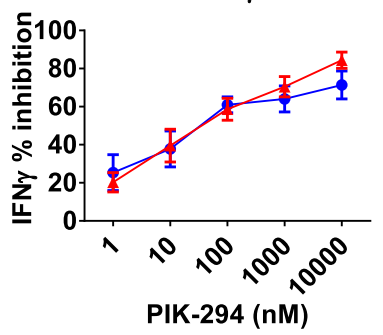

IL-13

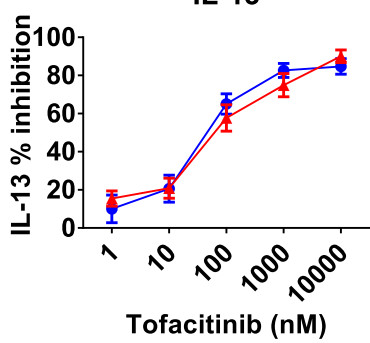

IL-13

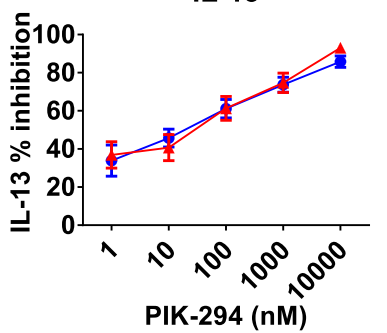

PIK-294 (nM)

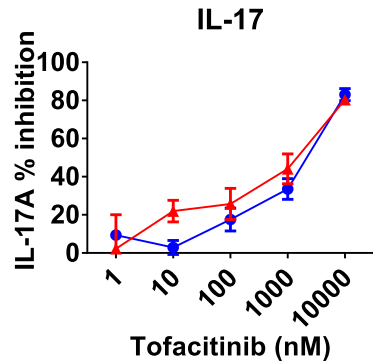

IL-17

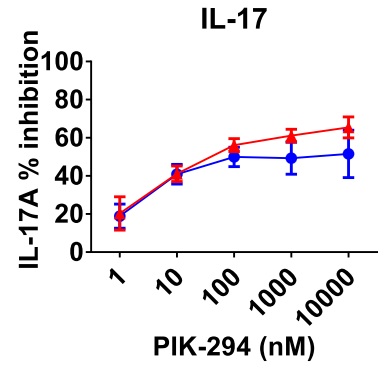

Healthy $\star$ Asthma

Fig. 1 Effects of PIK-294 and tofacinib on cytokine release in BAL cells from asthma patients $(n=12)$ and healthy subjects $(n=11)$. BAL cells were treated with varying concentrations of PIK-294 or tofacitinib for $1 \mathrm{~h}$ before being stimulated with antibodies against CD3 and CD28 to induce a TCR-specific response. Cytokines were measured by ELISA. Data is presented as mean \% inhibition (+/-SEM) of maximum cytokine release

tofacitinib $\mathrm{IC}_{35}$ and $\mathrm{IC}_{50}$ values are shown in Table 2; the values for IL-17 inhibition were generally higher compared to the other cytokines.

Toxicity tests showed that PIK-294 and tofacitinib had no cytotoxic effects on TCR-stimulated PBMCs at all concentrations tested (Additional file 4: Figure S1).

\section{Combination effects of dexamethasone and JAK or PI3K $\delta$ inhibitors on TCR responses}

The mean inhibitory effect of dexamethasone on all three cytokines was numerically greater in cells from controls compared to those from asthma patients, but these differences were not statistically significant (Fig. 2 and Table 2). Dexamethasone $\mathrm{IC}_{35}$ and $\mathrm{IC}_{50}$ values for IL-17 and IFNY (Table 2) were lower in healthy subjects compared to asthma. The effect of dexamethasone varied between cytokines, with IL-17 being inhibited less than IL-13 and IFNy (ANOVA analysis in healthy subjects and asthma; $p=0.0002$ and $p=0.0006$ respectively; Additional file 7: Figure S2). A notable difference was that dexamethasone was more potent than PIK-294 and tofacinib for inhibition of IL-13 from both asthma and healthy subjects, with at least 10 -fold lower $\mathrm{IC}_{50}$ values.

Table 2 Inhibition of cytokine production by dexamethasone, tofacitinib and PIK-294 in TCR-stimulated BAL cells from asthma patients and healthy subjects

\begin{tabular}{|c|c|c|c|c|c|c|c|}
\hline \multirow[t]{2}{*}{ Compound } & \multirow[t]{2}{*}{ Cytokine } & \multicolumn{2}{|c|}{$\mathrm{I}_{35}$ values $(\mathrm{nM})$} & \multicolumn{2}{|c|}{$\mathrm{IC}_{50}$ values $(\mathrm{nM})$} & \multicolumn{2}{|c|}{ Mean $\%$ inhibition at $10 \mu \mathrm{M}+/-\mathrm{SD}$} \\
\hline & & Healthy & Asthma & Healthy & Asthma & Healthy & Asthma \\
\hline \multirow[t]{3}{*}{ Dexamethasone } & IFNY & 2.6 & 3.4 & 7.6 & 28.7 & $75.2+/-20.8$ & $69.1+/-26.7$ \\
\hline & IL-13 & $<1.0^{\mathrm{a}}$ & $<1.0^{\mathrm{a}}$ & 1.1 & 1.2 & $96.6+/-6.8$ & $77.3+/-31.1$ \\
\hline & IL-17 & 8.7 & 267.8 & 1098 & $>10,000^{b}$ & $57.6+/-15.3$ & $45.8+/-21.7$ \\
\hline \multirow[t]{3}{*}{ Tofacitinib } & IFNy & 56.8 & 56.7 & 135.2 & 141.1 & $96.1+/-2.9$ & $94.9+/-7.2$ \\
\hline & IL-13 & 24.8 & 26.5 & 48.8 & 75.6 & $85.8+/-9.4$ & $90.0+/-11.5$ \\
\hline & IL-17 & 297 & 1042 & 1321 & 2495 & $80.4+/-9.2$ & $83.1+/-11.0$ \\
\hline \multirow[t]{3}{*}{ PIK-294 } & IFNY & 6.8 & 5.3 & 31.7 & 35.8 & $77.5+/-17.1$ & $84.4+/-14.5$ \\
\hline & IL-13 & 1.3 & $<1.0^{\mathrm{a}}$ & 19.0 & 31.2 & $87.4+/-9.3$ & $93.0+/-5.5$ \\
\hline & IL-17 & 9.6 & 10.1 & 368.4 & 75.9 & $61.3+/-14.7$ & $70.3+/-12.2$ \\
\hline
\end{tabular}

Absolute $\mathrm{IC}_{35}$ and $\mathrm{IC}_{50}$ values calculated from the mean $\%$ inhibition for each drug concentration tested. ${ }^{\mathrm{a}} \mathrm{I} \mathrm{C}_{35}$ value uncalculatable as $>35 \%$ mean inhibition observed with $1.0 \mathrm{nM}$ of drug; ${ }^{b} \mathrm{IC}_{50}$ value uncalculatable as $<50 \%$ mean inhibition observed with $10,000 \mathrm{nM}$ of drug 

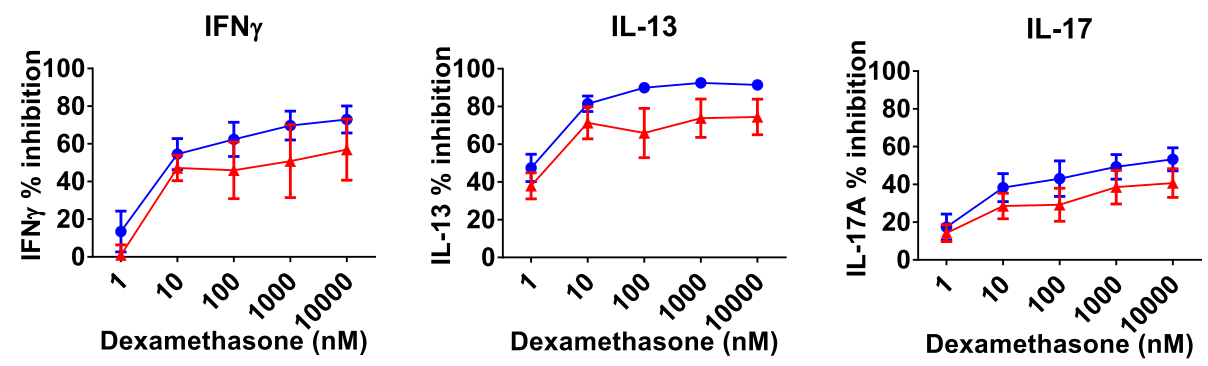

\section{Healthy $\neq$ Asthma}

Fig. 2 Effect of dexamethasone on cytokine release in BAL cells from asthma patients $(n=12)$ and healthy subjects $(n=11)$. BAL cells were treated with varying concentrations of dexamethasone for $1 \mathrm{~h}$ before being stimulated with antibodies against CD3 and CD28 to induce a TCRspecific response. Cytokines were measured by ELISA. Data is presented as mean \% inhibition (+/- SEM) of maximum cytokine release

There were sufficient BAL cells from 10 asthma patients, and 8 healthy subjects to perform combination experiments; cells were treated with increasing concentrations of dexamethasone plus 100nM of either tofacitinib (Fig. 3) or PIK-294 (Fig. 4); this concentration for tofacitinib and PIK-294 was chosen on the basis of causing submaximal inhibition, and for PIK-294, showing specificity for PI3K $\delta$ over other isoforms (see Fig. 1 and Additional file 3: Table S2).
Tofacitinib plus dexamethasone produced a greater effect than dexamethasone alone, with an additive effect on the inhibition of IL-13 and IFNY production from asthma and healthy cells; this additive effect on IL-13 from healthy cells was only apparent at low dexamethasone concentrations (Fig. 3). Tofacitinib caused an additive effect on the suppression of IL-17 production from healthy cells, but this was not seen with cells from asthma patients. It should be noted that the tofacitinib

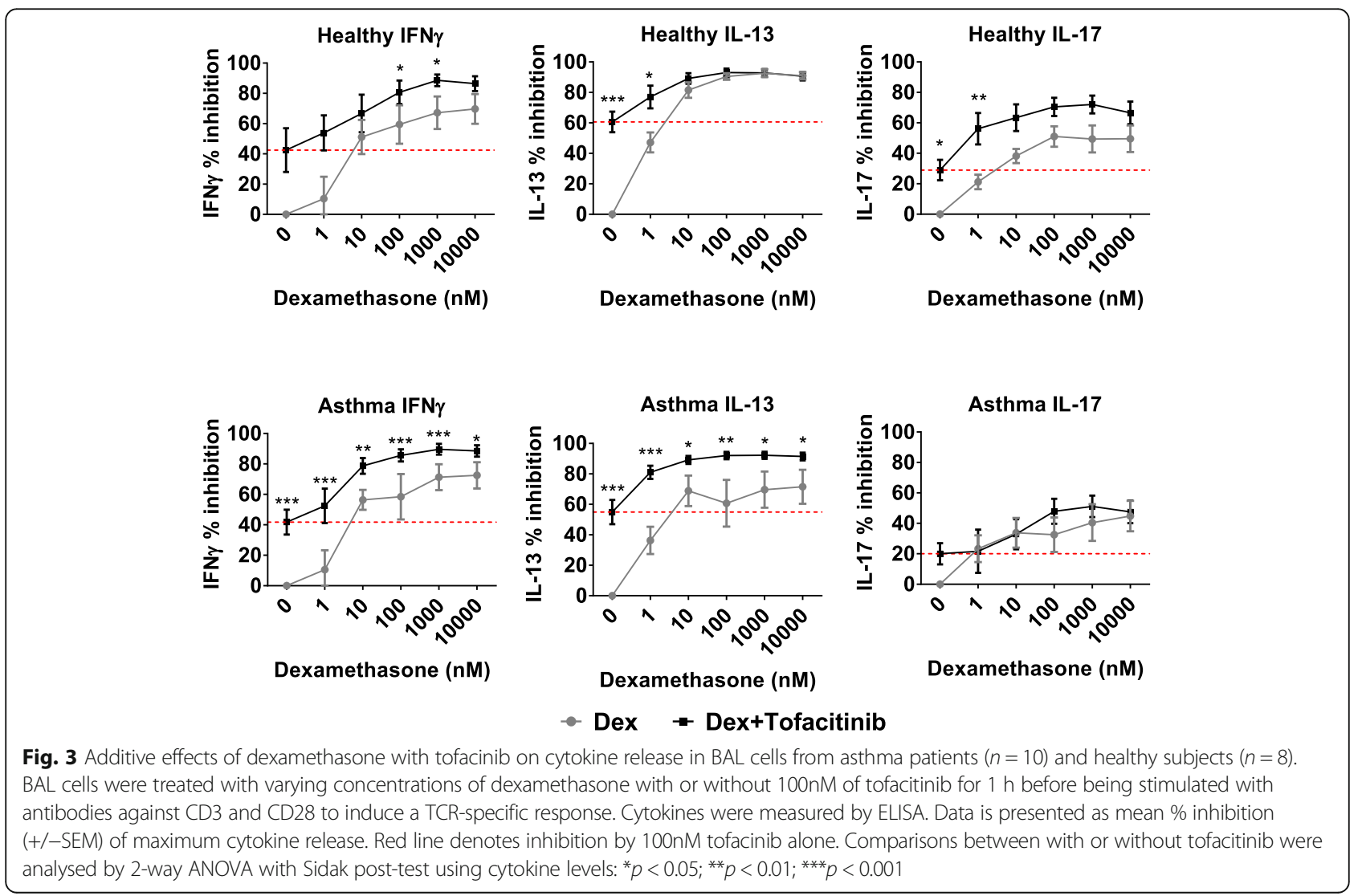



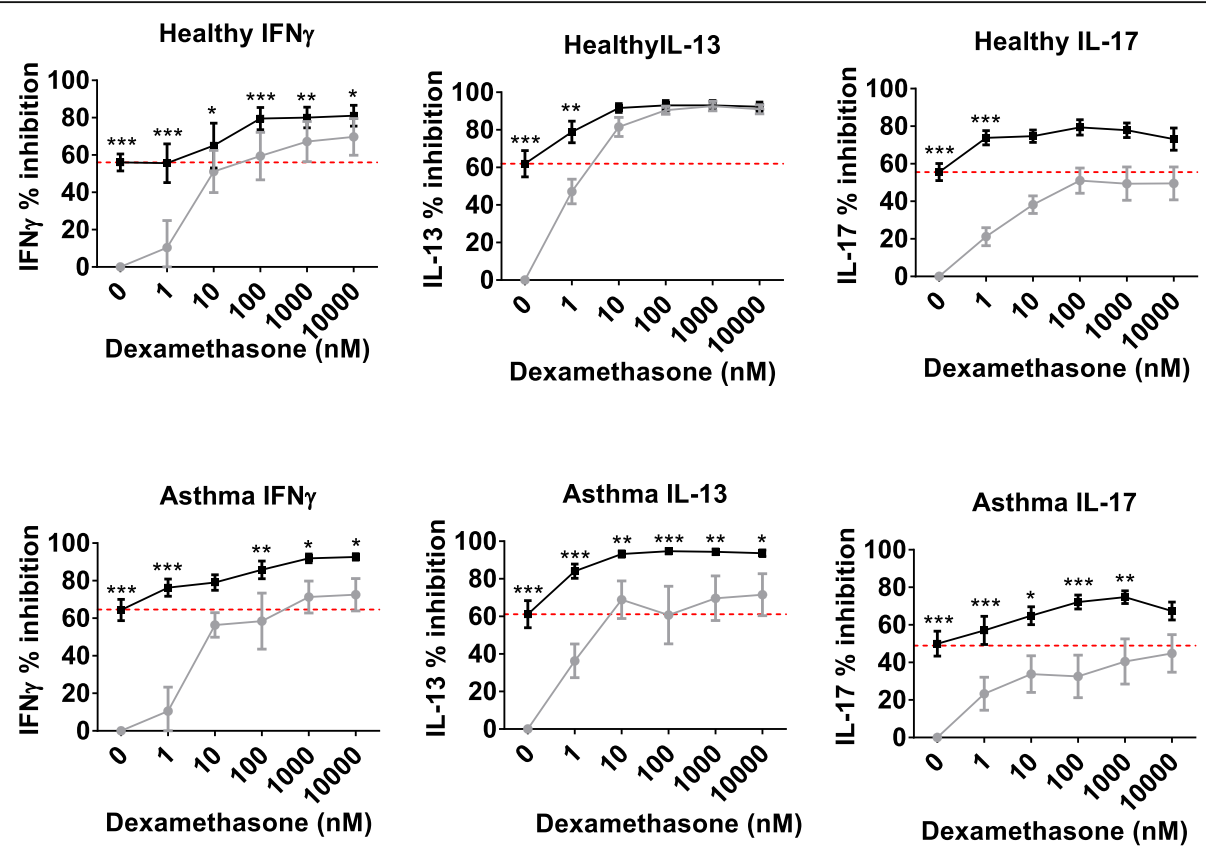

$\rightarrow$ Dex $\rightarrow$ Dex+PIK-294

Fig. 4 Additive effects of dexamethasone with PIK-294 on cytokine release in BAL cells from asthma patients $(n=10)$ and healthy subjects ( $n=8$ ). BAL cells were treated with varying concentrations of dexamethasone with or without 100nM of PIK-294 for $1 \mathrm{~h}$ before being stimulated with antibodies against CD3 and CD28 to induce a TCR-specific response. Cytokines were measured by ELISA. Data is presented as mean \% inhibition (+/-SEM) of maximum cytokine release. Red line denotes inhibition by 100nM PIK-294 alone. Comparisons between with or without PIK-294 were analysed by 2-way ANOVA with Sidak post-test using cytokine levels: ${ }^{*} p<0.05 ;{ }^{* *} p<0.01 ;{ }^{* * *} p<0.001$

concentration used (100nM) had little effect on IL-17 production from asthma cells when used without dexamethasone.

PIK-294 and dexamethasone combined caused additive suppression of all three cytokines measured from asthma and healthy cells; this additive effect on IL-13 from healthy cells was only apparent at low dexamethasone concentrations (Fig. 4).

\section{Lymphocyte specific effects of dexamethasone, PIK-294 and tofacinib}

Historically collected samples showed that lymphocytes typically account for only $2 \%$ of BAL cells in asthma patients and healthy subjects (Additional file 8: Table S5). The BAL cytokine work described above used a T-cell specific stimulant to initiate inflammatory responses in a mixed cell population. In this model, stimulated lymphocytes may activate other cell types, such as macrophages, which may be required for full lymphocyte activity. It is therefore possible that the inhibitory effects of the drugs on cytokine release were due to activity on non T-cells.

To demonstrate that TCR-induced cytokine release from BAL cells is T-cell dependent, BAL $(n=3)$, was depleted of $\mathrm{CD}^{+}$cells and the remaining cells treated with antibodies against CD3 and CD28 for $72 \mathrm{~h}$; the resulting levels of IFN $\gamma$, IL-13 and IL-17 were all undetectable (data not shown). Attempts were made to isolate purified lymphocytes from BAL in order to investigate cytokine production after TCR stimulation. However, due to the low lymphocyte and high macrophage composition of the BAL (approximately 2 and $>80 \%$ respectively), a maximum lymphocyte purity of only $50 \%$ was achievable. We therefore studied the effects of dexamethasone, PIK-294 and tofacinib on cytokine release from T-cells purified from the blood of asthma patients $(n=5)$. TCRstimulation of isolated lymphocytes did not induce IFN $\gamma$, IL-13 or IL-17 (data not shown); suggesting that crosstalk between T-cells and other cells such as monocytes or macrophages is required to enable TCR-induced cytokine production.

To demonstrate that the drugs had a direct effect on lymphocytes, TCR-induced STAT5 phosphorylation in purified T-cells, from the blood of asthma patients $(n=$ 5 ) and healthy subjects $(n=6)$, was examined (Fig. 5). STAT5 is activated following TCR-induced production of IL-2, and is an early stage marker of T-cell proliferation [17]. The levels of STAT5 activation in T-cells were similar for both groups. Tofacinib $(1 \mu \mathrm{M})$, inhibited STAT5 phosphorylation by 90.4 and $88.0 \%$ in asthma and healthy cells respectively, while dexamethasone ( $1 \mu \mathrm{M})$ reduced activation by $74.2 \%$ (asthma) and $76.0 \%$ (healthy) and PIK-294 $(1 \mu \mathrm{M})$ by $70.3 \%$ (asthma) 


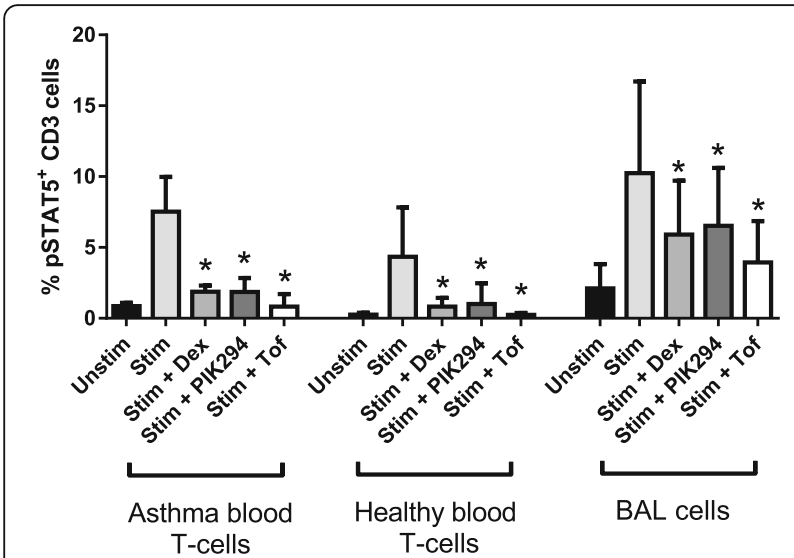

Fig. 5 Effects of dexamethasone, PIK-294 and tofacinib on TCRinduced PSTAT5 activation in lymphocytes. Isolated blood T-cells from asthma patients $(n=5)$ and healthy subjects $(n=6)$ and BAL cells ( $n=4$ asthma plus $n=3$ healthy) were treated with 1000nM dexamethasone, PIK-294 or tofacinib for $1 \mathrm{~h}$ before TCR-stimulation for $4 \mathrm{~h}$. Levels of phosphorylated STAT5 in $\mathrm{CD}^{+}$cells were quantified by flow cytometry. Data is presented as mean \% pSTAT5 positive CD3 cells $+/-$ standard deviation. Drug effects were assessed by 1-way ANOVA with a Dunnett's multiple comparison test against the stimulated no drug control: ${ }^{*} p<0.05$

and $78.2 \%$ (healthy). Inhibition of pSTAT5 in CD3 cells was also seen following TCR-stimulation of mixed BAL cells (Fig. 5).

TCR-stimulated BAL cells, from asthma patients $(n=$ 5), were used to investigate whether the drugs had any effect on cytokines from other cell types, which could subsequently influence lymphocyte activity. We measured levels of IL-12, which stimulates IFN $\gamma$ production in Th1 cells, and IL- 6 and TGF- $\beta$, which govern IL-17 production in Th17 cells. IL-12, IL- 6 and TGF- $\beta$ are all produced by macrophage and other antigen presenting cells found in BAL [18-20]. IL-6 levels were not increased following TCR-stimulation of BAL cells, and release was not inhibited by dexamethasone, PIK-294 or tofacinib (Additional file 9: Figure S3). IL-12 and TGF- $\beta$ levels were undetectable (data not shown).

\section{Expression of PI3K, pAKT and pSTAT proteins in bronchial biopsies from asthma patients and healthy subjects}

Expression of pSTAT1, 3, 5 and 6, as well as pAKT, $\mathrm{PI} 3 \mathrm{~K} \delta$ and PI3K $\gamma$, were assessed by immunohistochemistry in bronchial biopsies from healthy subjects $(n=12)$ and asthma patients $(n=13)$. Expression of all 7 proteins was detectable in airway epithelial cells and in infiltrating inflammatory cells, within the subepithelium, for both groups (see Additional file 10: Figure S4). Airway smooth muscle cells displayed clear nuclear expression of PI3K $\delta$ and diffused cytoplasmic expression of pSTAT5 and pSTAT6 only.
The number of cells expressing PI3K $\delta$ was higher in asthma patients compared to healthy subjects in both the epithelium (median expression 747 cells/mm vs 314 cells $/ \mathrm{mm} p=0.0005$ ) and subepithelial areas (median expression 314 cells $/ \mathrm{mm}^{2}$ vs 119 cells $/ \mathrm{mm}^{2} p=0.0012$ ) (Fig. 6). No differences were found between groups for any of the other proteins measured ( $p>0.05$ for all comparisons) (Additional file 11: Table S6).

To further assess $\mathrm{PI} 3 \mathrm{~K} \delta$ expression in subepithelial lymphocytes, dual label immunohistochemistry was carried out on bronchial biopsies for $\mathrm{CD} 3$ and $\mathrm{PI} 3 \mathrm{~K} \delta$ (Fig. 7a-d); the percentage of CD3 cells expressing PI3K $\delta$ and the absolute numbers of $\mathrm{CD} 3 / \mathrm{PI} 3 \mathrm{~K} \delta$ dual positive cells were similar in asthma and healthy samples. Sample numbers (asthma $n=9$, healthy $n=10$ ) are lower than in Fig. 6, due to insufficient tissue from some donors.

For participants who donated BAL for cytokine release experiments and biopsies for CD3 analysis ( $n=7$ asthma; $n=7$ healthy), comparisons were made between cytokine release and PI3K $\delta$ expression. Neither the number of PI3K $\delta$-positive CD3 cells, nor the percentage of CD3 cells expressing $\mathrm{PI} 3 \mathrm{~K} \delta$, correlated with the levels of TCR-stimulated IFN $\gamma$, IL-13 or IL-17 released ( $p>0.05$ for all comparisons).

PI3K $\delta$ expression was also examined in BAL CD3 cells by flow cytometry; these samples differed from those used for cytokine analysis. There was a small, but significant, increase in the percentage of BAL CD3 cells expressing $\mathrm{PI} 3 \mathrm{~K} \delta$ in asthma $(n=9)$ samples, compared to healthy samples $(n=6), 92.8+/-2.0 \%$ and $87.0+/-5.4 \%$ respectively (Fig. $7 \mathrm{e} ; p=0.01$ ). Analysis of PI3K $\delta$-specific fluorescence in $\mathrm{PI} 3 \mathrm{~K} \delta$ positive CD3 cells suggests that T-cells from asthma patients express higher levels of $\mathrm{PI} 3 \mathrm{~K} \delta$ protein than cells from healthy individuals $(p=$ 0.009) Fig. 7f).

\section{Discussion}

Inhibition of JAK or PI3K $\delta$ suppressed cytokine production from BAL cells of patients with moderate to severe asthma and reduced T-cell activation. Furthermore, there were additive anti-inflammatory effects when JAK and $\mathrm{PI} 3 \mathrm{~K} \delta$ inhibitors were used in combination with corticosteroids. Numbers of PI3K $\delta$ expressing cells were increased in the airways of asthma patients compared to controls, as well as levels of PI3K $\delta$ protein in BAL CD3 cells, indicating increased activity of this signalling pathway. Overall, these findings indicate considerable potential to use PI3K $\delta$ and JAK inhibitors to target T-cell associated inflammation in asthma. The major findings and limitations of the study are now discussed.

In this study, we used a mixed BAL cell model to assess the anti-inflammatory effects of PIK-294 and tofacinib. We believe that this is a more physiologically relevant model than using isolated T-cells for the 


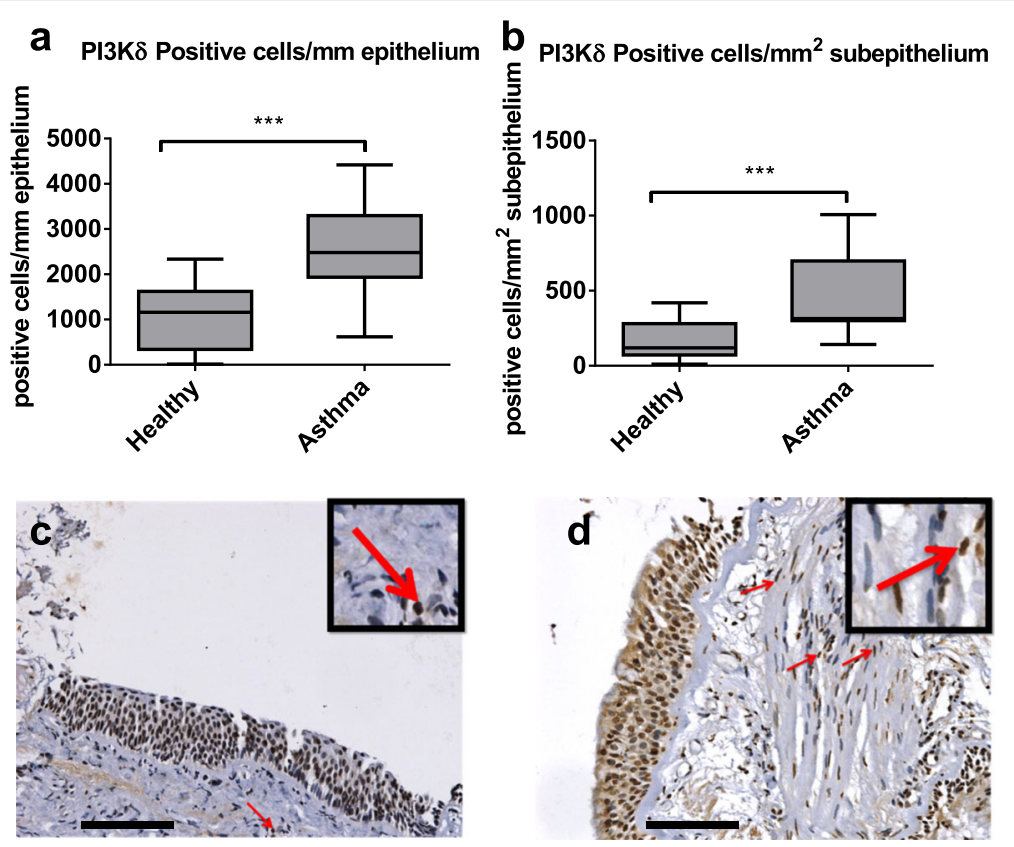

Fig. 6 Expression of PI3K $\delta$ in bronchial biopsies from asthma patients $(n=13)$ and healthy subjects $(n=12)$. PI3K $\delta$ expression was examined in bronchial tissue by immunohistochemistry. Results are presented as positive cells per $\mathrm{mm}$ of epithelium (a) and positive cells per $\mathrm{mm}^{2}$ of subepithelium (b).

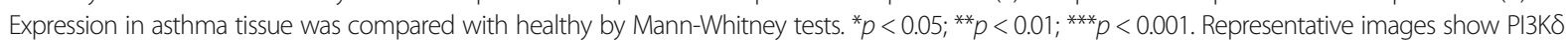
expression in bronchial tissue from healthy subjects (c) and asthma patients (d). Arrows and amplified images highlight positive staining in the subepithelial inflammatory cells. Black bars represent $100 \mu \mathrm{m}$

following reasons: firstly, anti-inflammatory treatments for asthma, such as corticosteroids, and potentially JAK and PI3K $\delta$ inhibitors, do not target specific cell types, such as lymphocytes, but have wide ranging effects on different inflammatory cells. Secondly, cross-talk between various cells types influences the inflammatory response, and these effects cannot be observed in single cell type models.

\section{PI3K inhibition}

PI3K $\delta$ is known to be involved in TCR-associated lymphocyte activation. We showed that PI3K $\delta$ inhibition suppresses IFN $\gamma$, IL-13 and IL-17 release from BAL cells. Using peripheral blood T-cells, it has been shown that a PI3K $\delta$ selective inhibitor inhibits TCR stimulated IFN $\gamma$ and IL-17 production from healthy subjects, and IL-5 and IL-13 production from patients with allergy [11]. Furthermore, the TH1 and TH17 responses of T-cells from the synovial fluid of rheumatoid arthritis patients were also suppressed by PI3K $\delta$ selective inhibition [11]. We now show that PI3K $\delta$ selective inhibition also has a broad range of effects on TH1, TH2 and TH17 responses in lung cells from healthy subjects and asthma patients.

We demonstrated that PIK-294 inhibited TCR-specific activation of lymphocytes isolated from PBMCs by measuring STAT5 phosphorylation in lymphocytes.
However, CD3/CD28 stimulation did not result in upregulation of cytokine production in isolated lymphocytes, suggesting that other cell types, such as monocytes/macrophages, are required to facilitate lymphocyte cytokine production after TCR stimulation. Previous work has shown that PI3K $\delta$ is involved in the activation of monocytes/macrophage following direct contact with stimulated T-cells [21], highlighting the interaction between these cell types in inflammatory responses. However, we showed that PIK-294 had no effect on cytokines that are known to influence $\mathrm{T}$ cell responses, and conclude that the effect of this PI3K $\delta$ inhibitor on IFN $\gamma$, IL-13 and IL-17 production in the supernatant of TCR-stimulated BAL cells is most likely through direct effects on lymphocytes.

PI3K $\delta$ expression was elevated in the epithelium and sub-epithelium of bronchial biopsies of asthma patients compared to healthy subjects. There is evidence to support increased expression of PI3K $\delta$ in COPD alveolar macrophages [22] and COPD blood neutrophils [23] compared to controls, but to our knowledge there are no similar data in asthma. PI3K $\gamma$ expression was not elevated in asthma tissue compared to controls, suggesting that PI3K $\delta$ is the dominant isoform that is upregulated in asthma. The numbers of subepithelial CD3 cells expressing PI3K $\delta$ did not differ between asthma and healthy tissue, suggesting that the elevation of PI3K $\delta$ in 

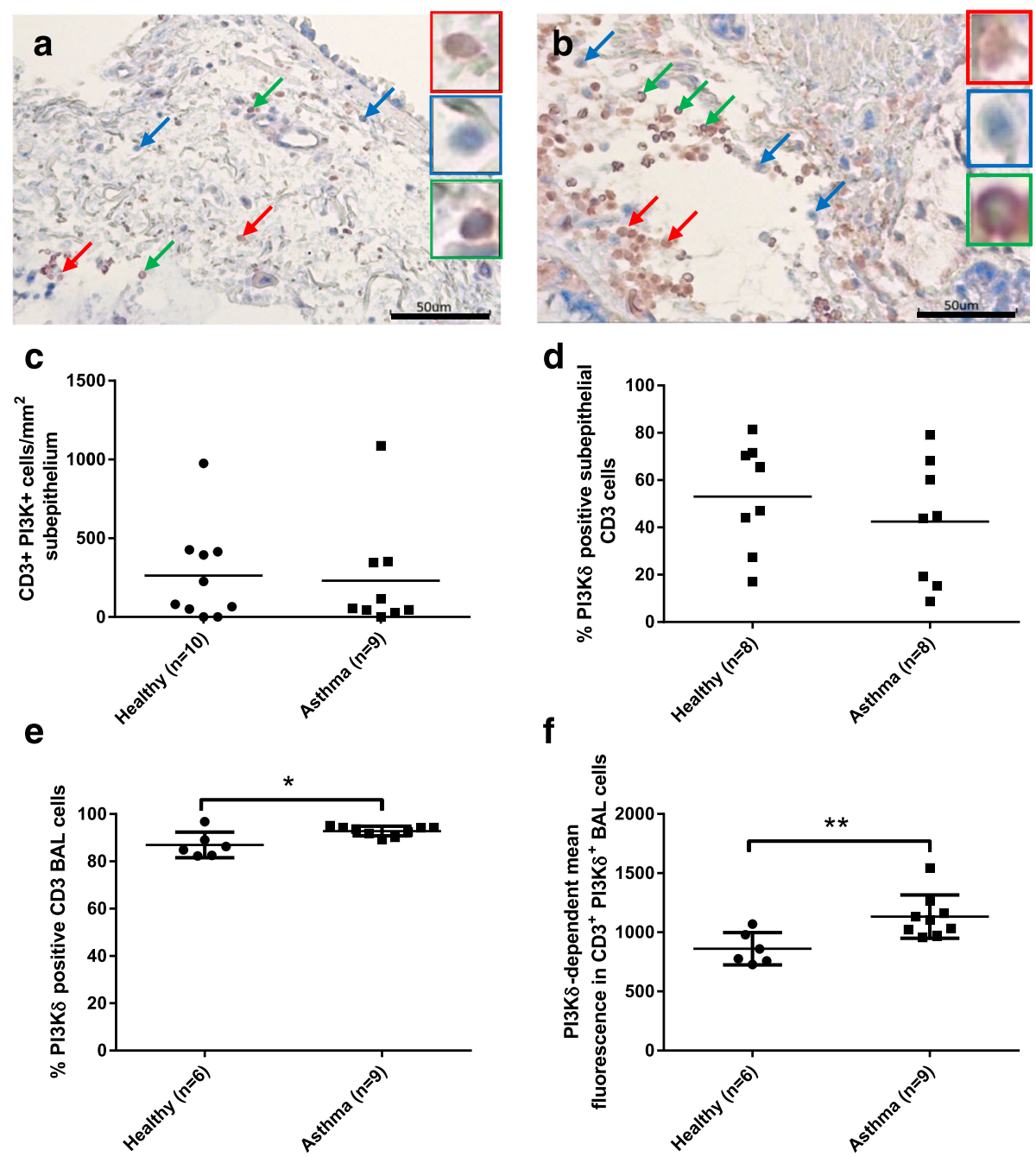

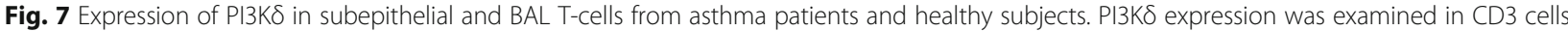
in subepithelial bronchial tissue and BAL by immunohistochemistry and flow cytometry, respectively. Representative images show PI3K $\delta$ expression in bronchial tissue from healthy subjects (a) and asthma patients (b). Arrows and amplified images highlight example staining: Red for CD3 only; Blue for

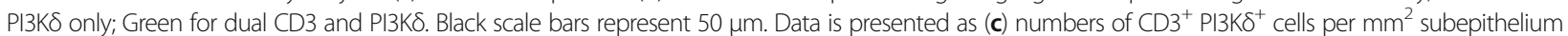
(Healthy $n=10$; Asthma $n=9$ ); (d) percentage of subepithelial CD3 cells expressing PI3K $\delta$ (Healthy $n=8$; Asthma $n=8$ ); (e) percentage of BAL CD3 cells

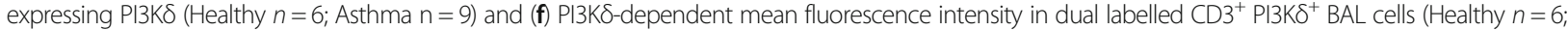
Asthma $n=9$ ), with bar illustrating mean values. The percentage of subepithelial CD3 cells expressing PI3K $\delta$ could not be calculated for $n=2$ healthy and $n=1$ asthma, due to lack of CD3 cells. Differences between healthy and asthma were assessed by T-test: ${ }^{*} p<0.05 ;{ }^{* *} p<0.01$

asthma tissue is due to an increase in other cell types which express PI3K $\delta$, such as neutrophils or macrophages. In BAL, however, the percentage of CD3 cells expressing PI3K $\delta$ was slightly increased in asthma compared to healthy samples, and, potentially more interestingly, $\mathrm{CD}^{+}{ }^{+} \mathrm{PI} 3 \mathrm{~K}^{+} \delta^{+} \mathrm{BAL}$ cells from asthma patients expressed higher levels of PI3K $\delta$ protein than cells from healthy subjects. Increased PI3K $\delta$ activity is the cause of $\mathrm{PI} 3 \mathrm{~K} \delta$ syndrome, which is characterised by repeat respiratory infections and progressive airway damage [24]. Potentially, the occurrence of similar characteristics in more severe asthma patients may be linked to increased
PI3K $\delta$ levels demonstrated in our study; this requires further investigation.

Interestingly, PI3K $\delta$ expression was increased in epithelial cells, as well as infiltrating inflammatory cells, from asthma patients. We set out a priori to investigate the effects of PI3K $\delta$ inhibition on BAL cells, and collected cell culture samples specifically for this purpose. We did not collect epithelial cells for culture, but our positive findings for this cell type indicate that further studies with bronchial epithelial cells are required to explore the function of $\mathrm{PI} 3 \mathrm{~K} \delta$ in asthma patients. 


\section{JAK inhibition}

TCR-stimulated release of IFNy, IL-13 and IL-17 from BAL cells was JAK-dependent. IL-2 is a key cytokine involved in lymphocyte activation and proliferation, and signals through the IL-2 receptor/JAK/STAT5 pathway. We demonstrated that tofacitinib inhibited this IL-2 signalling pathway in T-cells isolated from PBMCs and $\mathrm{CD}^{+} \mathrm{BAL}$ cells, supporting a direct pharmacological effect of this drug on lymphocytes causing cytokine suppression in BAL cells. There was notable suppression of the $\mathrm{TH} 1$ and $\mathrm{TH} 2$ responses, with over $80 \%$ inhibition of IFN $\gamma$ and IL-13 secretion. Inhibiting TH1 responses may be therapeutically important in asthma; Raundhal et al. [2] recently demonstrated that BAL from severe asthma patients contains more IFNY producing lymphocytes, than BAL from mild asthma patients. JAK inhibitors could potentially be used to target this component of the immune response in severe asthma.

The effects of tofacitinib on IL-17 production at concentrations of $1 \mu \mathrm{M}$ and below were modest, although there was a sharp rise in efficacy at $10 \mu \mathrm{M}$. This indicates low potency for this drug on IL-17 production, confirmed by the high $\mathrm{IC}_{35}$ values $>0.25 \mu \mathrm{M}$; this contrasts sharply with low nanomolar tofacitinib $\mathrm{IC}_{35}$ values for other cytokines (see Table 2), and suggests that JAK inhibitors may not reduce IL-17-driven responses in asthma.

There was no difference in activated STAT1, 3, 5 and 6 levels in bronchial biopsies from asthma patients compared to controls. Previous studies involving lung tissue from asthma patients have also failed to find elevated levels of pSTAT1 [25], although Sampath et al. [26] reported increased expression in steroid naïve asthma compared to controls. It is possible that high ICS doses used by patients in our study inhibited STAT1 activity. Rhinovirus infection of epithelial cells increases STAT1 expression [27], and increases in STAT1 activity may be more prominent during viral induced exacerbations of asthma.

Ruwanpura et al. [28] showed that pSTAT3 expression in COPD lung tissue is related to the degree of airway inflammation; perhaps our negative findings are indicative of low grade inflammation in the patients sampled. It has been reported that total STAT6 expression is increased in the bronchial epithelium of asthma patients compared to controls [29,30], but others could not reconfirm this result [31]. Interestingly, inhaled allergen challenge in asthma patients induces pSTAT6 expression in epithelial cells [32], demonstrating dynamic regulation of STAT-associated activity with airway inflammation. Our study focused on phosphorylated STAT6, and found no difference between groups. Overall, our results suggest that the dynamic regulation of STAT protein phosphorylation interferes with the ability to detect STAT dysregulation by immunohistochemistry in this context.

\section{Combination therapy}

We have previously shown that T-cell receptor stimulation of BAL cells causes IL-13 production that is less sensitive to corticosteroids in asthma patients compared to controls [33]. The current study showed numerical trends for reduced corticosteroid effects in asthma, but these did not reach statistical significance, perhaps due to variation in a limited sample size. In our study, IL-13 production was greater in asthma cells compared to controls. Potentially, this additional production is induced by corticosteroid insensitive mechanisms, which caused reduced efficacy of dexamethasone in our experiments. Unlike corticosteroid sensitive patients, systemic prednisolone treatment does not reduce IL-13 production in corticosteroid resistant asthma [34]. The low nanomolar $\mathrm{IC}_{35}$ values of dexamethasone for IL-13 in asthma patients should be noted, but the maximal efficacy at the higher concentrations was only approximately $75 \%$ inhibition, compared to over $90 \%$ in healthy samples. IL-13 is involved in allergic responses, fibrosis and mucus hypersecretion [35]. Our results suggest that corticosteroid use in clinical practice is unlikely to completely inhibit IL-13 production from lymphocytes, even at high doses.

Corticosteroid suppression of IL-17 was lower compared to other cytokines. This variation in corticosteroid effects on different cytokines has been observed in other cell types $[19,36]$, and may be due to differences in the signaling pathways that control cytokine gene expression. Recent studies have shown that CD4 cells from steroid insensitive asthma patients release more IL-17 than cells from steroid sensitive patients [37] and that, unlike TH2 cells, IL-17 producing BAL T-cells from severe asthma patients are insensitive to corticosteroid-induced cell death [38]. The clinical implication of these findings is that TH17 inflammation in asthma is relatively corticosteroid insensitive.

There were increased anti-inflammatory effects when combining corticosteroid with either tofacitinib or PIK294, compared to either drug alone; these additive effects may be useful in clinical practice, as drugs of these classes may be used in combination with corticosteroids. Due to cell number limitations we were unable to perform analysis using multiple concentrations of both dexamethasone and kinase inhibitors to determine whether these combination effects are truly additive or synergistic.

Previous studies have shown that PI3K $\delta$ inhibition can enhance the effects of corticosteroids; this has been observed using COPD peripheral blood monocytes and monocytic cell lines exposed to oxidative stress [22] The current data shows an additive effect of these two classes of drugs in asthma lymphocytes. 
Previous studies using other immune cells types have also shown that JAK inhibitors combine with corticosteroids to provide enhanced anti-inflammatory effects $[25,39]$. Tofacitinib had low potency on IL-17 production, and consequently did not have an additive effect on IL-17 production when combined at $100 \mathrm{nM}$ concentration with dexamethasone. In contrast, PI3K $\delta$ inhibition combined with dexamethasone to provide additive anti-inflammatory effects on all cytokines including IL-17, suggesting promise for this drug combination for suppressing IL-17 production in asthma.

\section{Conclusion}

Inhibition of either JAK or PI3K $\delta$ signalling suppresses cytokine production from asthma and healthy BAL cells, and reduces $\mathrm{T}$-cell activation. We provide evidence of additive effects when these drugs are combined with corticosteroids. These results promote the development of these drug classes for the treatment asthma. The upregulation of PI3K $\delta$ expression in the airways of asthma patients further underscores the potential of targeting this kinase to suppress inflammation in this disease.

\section{Additional files}

Additional file 1: Table S1. Demographics and clinical features of blood donating subjects and donors of historically collected BAL cytospins. (DOC $33 \mathrm{~kb}$ )

Additional file 2: Supplementary Method. (DOC $47 \mathrm{~kb}$ )

Additional file 3: Table S2. In vitro enzymatic profiles for tofacitinib and PIK-294. (DOC 35 kb)

Additional file 4: Figure S1. Cytotoxic effects of PIK-294, tofacinib and dexamethasone. PBMCs from healthy subjects $(n=3)$ were treated with PIK-294, tofacinib or dexamethasone for $1 \mathrm{~h}$ prior to TCR-stimulation for $72 \mathrm{~h}$. Cytotoxicity was assessed by LDH assay (A) or propidium iodide flow cytometry assay (B). Cytotoxic effects were assessed by 1-way ANOVA with Dunnett's post-hoc test against the no drug DMSO control. All non-significant. (PPTX $211 \mathrm{~kb}$ )

Additional file 5: Table S3. Immunohistochemistry retrieval buffers and antibody dilutions. (DOC $34 \mathrm{~kb}$ )

Additional file 6: Table S4. Baseline and TCR-stimulated Cytokine levels in BAL cells. (DOC $35 \mathrm{~kb}$ )

Additional file 7: Figure S2. Comparison of \% inhibition of IFNY, LL-13 and IL-17 for dexamethasone, tofacitinib and PIK-294. BAL cells from asthma patients $(n=12)$ and healthy subjects $(n=11)$ were treated with dexamethasone, tafacitinib or PIK-294 for $1 \mathrm{~h}$ before being stimulated with antibodies against CD3 and CD28 to induce a TCR-specific response. Cytokines were measured by ELISA and data is presented as the mean (+/- SEM) \% inhibition in relation to the stimulated no drug control. (PPTX $742 \mathrm{~kb}$ )

Additional file 8: Table S5. BAL Differential Cell Counts from historically collected samples. (DOC $29 \mathrm{~kb}$ )

Additional file 9: Figure S3. Effects of Dexamethasone, PIK-294 and tofacinib on IL-6 from TCR-stimulated BAL cells. BAL cells from asthma patients $(n=5)$ were treated with varying concentrations of dexamethasone with or without $100 \mathrm{nM}$ of tofacitinib for $1 \mathrm{~h}$ before being stimulated with antibodies against CD3 and CD28 to induce a TCR-specific response. IL-6 was measured by ELISA. Data is presented as mean $+/-$ standard deviation. Drug effects were analysed by 1-way ANOVA: $p=0.22$. (PPTX $89 \mathrm{~kb}$ )
Additional file 10: Figure S4. Representative images for Immunohistochemistry negative controls. Bronchial biopsy tissue was stained using primary antibodies against PI3Kס, PI3KY, PAKT, STAT1, STAT3, STAT5 and STAT6. Sequential sections were used for negative controls using either an isotype control negative antibody at the same concentration as the various primary antibodies, or with the omission of the primary antibody. Negative controls for each primary antibody were assessed in sequential tissue sections from $n=3$ patients. Black bar represents $100 \mu \mathrm{m}$. (PPTX $487 \mathrm{~kb}$ )

Additional file 11: Table S6. Expression of PSTATs, PAKT, PI3KY and PI3Ky by immunohistochemistry in bronchial biopsies. (DOC $41 \mathrm{~kb}$ )

\section{Abbreviations}

ACQ: Asthma control questionnaire; BAL: Bronchoalveolar lavage; $\mathrm{FEV}_{1}$ : Forced expiratory volume in 1 second; FVC: Forced vital capacity; GR: Glucocorticoid receptor; IC: Inhibitory concentration; ICS: Inhaled corticosteroids; IFNY: Interferon gamma; IL: Interleukin; JAK: Janus-activated kinases; LABA: Long acting $\beta$-agonist; N/A: Not applicable; PAKT: Phophorylated protein kinase B; PBMC: Peripheral blood mononuclear cells; $\mathrm{PD}_{20}$ : Provocative Dose to induce $20 \%$ fall in $\mathrm{FEV}_{1}$; PI3KY: Phosphatidylinositol 3-kinase gamma; PIKKס: Phosphatidylinositol 3-kinase delta; SABA: Short acting $\beta$-agonist; SD: Standard deviation; SOCS: Suppressor of cytokine signalling; STAT: Signal transducer and activator of transcription; TCR: Tcell receptor; TH1: T-helper 1; TH17: T-helper 17; TH2: T-helper 2

\section{Acknowledgements}

This report is independent research supported by National Institute for Health Research South Manchester Respiratory and Allergy Clinical Research Facility at University Hospital of South Manchester NHS Foundation Trust. The views expressed in this publication are those of the author(s) and not necessarily those of the NHS, the National Institute for Health Research or the Department of Health.

\section{Funding}

This work was partially funded by Almiral S.A., Barcelona, Spain and the North West Lung Research Charity, Manchester, UK.

\section{Availability of data and material}

The datasets analysed during the current study are available from the corresponding author on reasonable request.

\section{Authors' contributions}

TS participated in the design of the study, carried out BAL cell cultures and ELISAs, performed the statistical analysis and drafted the manuscript. JP participated in the design of the study and carried of immunohistochemistry analysis. VG participated in the study's design and analysis of data. JP participated in immunohistochemistry analysis. DS, IR, MDL and MM conceived the study, and participated in its design and coordination and helped to draft the manuscript. All authors read and approved the final manuscript.

\section{Competing interests}

D. Singh has received sponsorship to attend international meetings, honoraria for lecturing or attending advisory boards and research grants from various pharmaceutical companies including Almirall, AstraZeneca, Boehringer Ingelheim, Chiesi, Genentech, GlaxoSmithKline, Glenmark, Johnson and Johnson, Merck, NAPP, Novartis, Pfizer, Skypharma, Takeda, Teva, Therevance and Verona. I. Ramis, M. D. Lehner and M. Miralpeix are employees of Almirall S. A. T. Southworth, J. Plumb, V. Gupta and J. Pearson declare that they have no competing interests.

\section{Consent for publication}

Not applicable.

\section{Ethics approval and consent to participate}

The study and sample collection was approved by local research ethics committees (Bronchoscopy: NRES Committee North West - Greater Manchester South; REC Ref: 06/Q1403/156; Blood: North West Preston Research Ethics Committee, REC Ref: 10/H1016/25; Resected lung tissue for immunohistochemistry controls: South Manchester Research Ethics Committee, REC Ref: 03/SM/396) and all subjects provided written informed consent. 


\section{Author details}

'The University of Manchester; Division of Infection, Immunity \& Respiratory Medicine; Manchester Academic Health Science Centre; University Hospital South Manchester NHS Foundation Trust, Southmoor Road, Manchester M23 9LT, UK.

${ }^{2}$ Almirall R\&D Center, Sant Feliu de Llobregat, Barcelona, Spain.

Received: 5 May 2016 Accepted: 17 September 2016

Published online: 04 October 2016

\section{References}

1. Fahy JV. Type 2 inflammation in asthma-present in most, absent in many. Nat Rev Immunol. 2015;15:57-65.

2. Raundhal M, Morse C, Khare A, Oriss TB, Milosevic J, Trudeau J, Huff R, Pilewski J, Holguin F, Kolls J, et al. High IFN-gamma and low SLPI mark severe asthma in mice and humans. J Clin Invest. 2015;125:3037-50.

3. Vanaudenaerde BM, Verleden SE, Vos R, De Vleeschauwer SI, WillemsWidyastuti A, Geenens R, Van Raemdonck DE, Dupont L, Verbeken EK, Meyts I. Innate and adaptive interleukin-17-producing lymphocytes in chronic inflammatory lung disorders. Am J Respir Crit Care Med. 2011;183:977-86.

4. Reddy D, Little FF. Glucocorticoid-resistant asthma: more than meets the eye. J Asthma. 2013;50:1036-44

5. O'Shea JJ, Plenge R. JAK and STAT signaling molecules in immunoregulation and immune-mediated disease. Immunity. 2012;36:542-50.

6. Knosp CA, Johnston JA. Regulation of CD4+ T-cell polarization by suppressor of cytokine signalling proteins. Immunology. 2012;135:101-11.

7. Egwuagu CE. STAT3 in CD4+ T helper cell differentiation and inflammatory diseases. Cytokine. 2009;47:149-56.

8. Jarmin SJ, David R, Ma L, Chai JG, Dewchand H, Takesono A, Ridley AJ, Okkenhaug K, Marelli-Berg FM. T cell receptor-induced phosphoinositide-3kinase p110delta activity is required for $\mathrm{T}$ cell localization to antigenic tissue in mice. J Clin Invest. 2008;118:1154-64.

9. Okkenhaug K, Bilancio A, Farjot G, Priddle H, Sancho S, Peskett E, Pearce W, Meek SE, Salpekar A, Waterfield MD, et al. Impaired B and T cell antigen receptor signaling in p110delta PI 3-kinase mutant mice. Science. 2002;297:1031-4.

10. Garcon F, Patton DT, Emery JL, Hirsch E, Rottapel R, Sasaki T, Okkenhaug K. CD28 provides T-cell costimulation and enhances PI3K activity at the immune synapse independently of its capacity to interact with the p85/ p110 heterodimer. Blood. 2008;111:1464-71.

11. Soond DR, Bjorgo E, Moltu K, Dale VQ, Patton DT, Torgersen KM, Galleway F, Twomey B, Clark J, Gaston JS, et al. PI3K p110delta regulates T-cell cytokine production during primary and secondary immune responses in mice and humans. Blood. 2010;115:2203-13.

12. Lee KS, Lee HK, Hayflick JS, Lee YC, Puri KD. Inhibition of phosphoinositide 3-kinase delta attenuates allergic airway inflammation and hyperresponsiveness in murine asthma model. FASEB J. 2006;20:455-65.

13. Kim SR, Lee KS, Park HS, Park SJ, Min KH, Moon H, Puri KD, Lee YC. HIFlalpha inhibition ameliorates an allergic airway disease via VEGF suppression in bronchial epithelium. Eur J Immunol. 2010:40:2858-69.

14. Kudlacz E, Conklyn M, Andresen C, Whitney-Pickett C, Changelian P. The JAK-3 inhibitor CP-690550 is a potent anti-inflammatory agent in a murine model of pulmonary eosinophilia. Eur J Pharmacol. 2008;582:154-61.

15. Knight ZA, Gonzalez B, Feldman ME, Zunder ER, Goldenberg DD, Williams O, Loewith R, Stokoe D, Balla A, Toth B, et al. A pharmacological map of the PI3-K family defines a role for p110alpha in insulin signaling. Cell. 2006:125:733-47.

16. Meyer DM, Jesson MI, Li X, Elrick MM, Funckes-Shippy CL, Warner JD, Gross CJ, Dowty ME, Ramaiah SK, Hirsch JL, et al. Anti-inflammatory activity and neutrophil reductions mediated by the JAK1/JAK3 inhibitor, CP-690,550, in rat adjuvant-induced arthritis. J Inflamm (Lond). 2010:7:41.

17. Welte T, Leitenberg D, Dittel BN, al-Ramadi BK, Xie B, Chin YE, Janeway Jr CA, Bothwell AL, Bottomly K, Fu XY. STAT5 interaction with the T cell receptor complex and stimulation of $T$ cell proliferation. Science. 1999;283:222-5.

18. Plummeridge MJ, Armstrong L, Birchall MA, Millar AB. Reduced production of interleukin 12 by interferon gamma primed alveolar macrophages from atopic asthmatic subjects. Thorax. 2000;55:842-7.

19. Armstrong J, Sargent C, Singh D. Glucocorticoid sensitivity of lipopolysaccharide-stimulated chronic obstructive pulmonary disease alveolar macrophages. Clin Exp Immunol. 2009;158:74-83.

20. Hussell T, Bell TJ. Alveolar macrophages: plasticity in a tissue-specific context. Nat Rev Immunol. 2014;14:81-93.
21. Molnarfi N, Gruaz L, Dayer JM, Burger D. Opposite regulation of IL-1 beta and secreted IL-1 receptor antagonist production by phosphatidylinositide3 kinases in human monocytes activated by lipopolysaccharides or contact with T cells. J Immunol. 2007:178:446-54.

22. Marwick JA, Caramori G, Casolari P, Mazzoni F, Kirkham PA, Adcock IM, Chung KF, Papi A. A role for phosphoinositol 3-kinase delta in the impairment of glucocorticoid responsiveness in patients with chronic obstructive pulmonary disease. J Allergy Clin Immunol. 2010;125:1146-53.

23. Milara J, Lluch J, Almudever P, Freire J, Xiaozhong Q, Cortijo J. Roflumilast N-oxide reverses corticosteroid resistance in neutrophils from patients with chronic obstructive pulmonary disease. J Allergy Clin Immunol. 2014;134:314-22.

24. Angulo I, Vadas O, Garcon F, Banham-Hall E, Plagnol V, Leahy TR, Baxendale $\mathrm{H}$, Coulter T, Curtis J, Wu C, et al. Phosphoinositide 3-kinase delta gene mutation predisposes to respiratory infection and airway damage. Science. 2013:342:866-71.

25. Southworth T, Metryka A, Lea S, Farrow S, Plumb J, Singh D. IFN-gamma synergistically enhances LPS signalling in alveolar macrophages from COPD patients and controls by corticosteroid-resistant STAT1 activation. Br J Pharmacol. 2012;166:2070-83.

26. Sampath D, Castro M, Look DC, Holtzman MJ. Constitutive activation of an epithelial signal transducer and activator of transcription (STAT) pathway in asthma. J Clin Invest. 1999:103:1353-61.

27. Hudy MH, Traves SL, Proud D. Transcriptional and epigenetic modulation of human rhinovirus-induced CXCL10 production by cigarette smoke. Am J Respir Cell Mol Biol. 2014;50:571-82.

28. Ruwanpura SM, McLeod L, Miller A, Jones J, Vlahos R, Ramm G, Longano A, Bardin PG, Bozinovski S, Anderson GP, Jenkins BJ. Deregulated Stat3 signaling dissociates pulmonary inflammation from emphysema in gp130 mutant mice. Am J Physiol Lung Cell Mol Physiol. 2012;302:L627-39.

29. Mullings RE, Wilson SJ, Puddicombe SM, Lordan JL, Bucchieri F, Djukanovic R, Howarth PH, Harper S, Holgate ST, Davies DE. Signal transducer and activator of transcription 6 (STAT-6) expression and function in asthmatic bronchial epithelium. J Allergy Clin Immunol. 2001:108:832-8.

30. Christodoulopoulos P, Cameron L, Nakamura Y, Lemiere C, Muro S, Dugas M, Boulet LP, Laviolette M, Olivenstein R, Hamid Q. TH2 cytokine-associated transcription factors in atopic and nonatopic asthma: evidence for differential signal transducer and activator of transcription 6 expression. J Allergy Clin Immunol. 2001;107:586-91.

31. Tomita K, Caramori G, Ito K, Sano H, Lim S, Oates T, Cosio B, Chung KF, Tohda Y, Barnes PJ, Adcock IM. STAT6 expression in T cells, alveolar macrophages and bronchial biopsies of normal and asthmatic subjects. I Inflamm (Lond). 2012;9:5.

32. Phipps S, Benyahia F, Ou TT, Barkans J, Robinson DS, Kay AB. Acute allergeninduced airway remodeling in atopic asthma. Am J Respir Cell Mol Biol. 2004;31:626-32.

33. Kaur M, Reynolds S, Smyth LJ, Simpson K, Hall S, Singh D. The effects of corticosteroids on cytokine production from asthma lung lymphocytes. Int Immunopharmacol. 2014;23:581-4.

34. Naseer T, Minshall EM, Leung DY, Laberge S, Ernst P, Martin RJ, Hamid Q Expression of IL-12 and IL-13 mRNA in asthma and their modulation in response to steroid therapy. Am J Respir Crit Care Med. 1997;155:845-51.

35. Corren J. Role of interleukin-13 in asthma. Curr Allergy Asthma Rep. 2013;13:415-20.

36. Higham A, Lea S, Plumb J, Maschera B, Simpson K, Ray D, Singh D. The role of the liver $X$ receptor in chronic obstructive pulmonary disease. Respir Res. 2013;14:106

37. Chambers ES, Nanzer AM, Pfeffer PE, Richards DF, Timms PM, Martineau AR, Griffiths CJ, Corrigan CJ, Hawrylowicz CM. Distinct endotypes of steroidresistant asthma characterized by IL-17A (high) and IFN-gamma (high) immunophenotypes: Potential benefits of calcitriol. J Allergy Clin Immunol. 2015:136:628-37. e624.

38. Irvin C, Zafar I, Good J, Rollins D, Christianson C, Gorska MM, Martin RJ, Alam R. Increased frequency of dual-positive TH2/TH17 cells in bronchoalveolar lavage fluid characterizes a population of patients with severe asthma. J Allergy Clin Immunol. 2014;134:1175-86. e1177.

39. Clarke DL, Clifford RL, Jindarat $S$, Proud D, Pang L, Belvisi M, Knox AJ. TNFalpha and IFNgamma synergistically enhance transcriptional activation of CXCL10 in human airway smooth muscle cells via STAT-1, NF-kappaB, and the transcriptional coactivator CREB-binding protein. J Biol Chem. 2010; 285:29101-10. 